\title{
Lessons learnt from the Pietermaritzburg experience with damage control laparotomy for trauma
}

\author{
Ross D Weale, ${ }^{1}$ V Y Kong, ${ }^{2}$ J M Blodgett, ${ }^{3}$ J Buitendag, ${ }^{2}$ A Ras, G Laing, J L Bruce, \\ W Bekker, V Manchev, D Clarke ${ }^{2,4}$
}

'B Detachment, 256 Field

Hospital, London, UK

${ }^{2}$ Department of Surgery,

Pietermaritzburg Metropolitan

Trauma Service, Durban, South

Africa

${ }^{3}$ Department of Epidemiology,

MRC Unit, University College

London, London, United

Kingdom

${ }^{4}$ Department of Surgery, University of the Witwatersrand, Johannesburg, South Africa

\section{Correspondence to}

Captain Ross D Weale, 256 Field Hospital, London SE17 3RF, UK; rossweale@doctors.org.uk

Received 16 March 2018 Revised 24 May 2018 Accepted 25 May 2018

Published Online First

27 June 2018

Check for updates

To cite: Weale RD, Kong VY,

Blodgett JM, et al.

$J$ R Army Med Corps

2018:164:428-431

\begin{abstract}
Introduction The modern concept of damage control surgery (DCS) for trauma was first introduced less than three decades ago. This audit aims to describe the spectrum and outcome of patients requiring DCS, to benchmark our experience against that reported from other centres and countries and to distil the pertinent teaching lessons from this experience.
\end{abstract}

Methods All patients over the age of 15 years undergoing a laparotomy for trauma over the period from December 2012 to July 2016 were retrieved from the trauma registry of the Pietermaritzburg Metropolitan Trauma Service, South Africa. Physiological parameters and visceral injuries were assessed. Statistical analysis was performed using STATA V.15.0.

Results A total of 562 patients underwent trauma laparotomy during the period under review. The mechanism was penetrating trauma in $81 \%$ of cases (453/562). A great proportion of trauma victims were male $(503 / 562$, $90 \%$ ), with a mean age of $29.5 \pm 10.8$. A total of 99 of these $(18 \%)$ had a DCS procedure versus $463(82 \%)$ non-DCS. Out of the 99 who required DCS, there were 32 mortalities (32\%). The mean physiological parameters for the DCS patient demonstrated acidosis ( $\mathrm{pH} 7.28 \pm 0.15)$ with a raised lactate $(5.25 \mathrm{mmol} / \mathrm{L} \pm 3.71)$. Our primary repair rates for enteric injuries were surprisingly high.

Conclusion Just under $20 \%$ of trauma laparotomies require DCS. In this cohort of patients, the mortality rate is just under one-third. Further attention must be paid to refining the appropriate indications for DCS as the margin for error in such a cohort is very small and poor decision-making is difficult to correct. The major lesson from this analysis is that the decision to perform DCS must be made early and communicated appropriately to all those managing the patient.

\section{INTRODUCTION}

The modern concept of damage control surgery (DCS) for trauma was first introduced three decades ago. Since then, it has become widely accepted. The principle underlying DCS is that a prolonged operation in a patient with profound physiological derangements must be avoided. Instead, an abbreviated procedure must be undertaken to control bleeding and soiling and once this has been achieved definitive repair is delayed until such a time as the patient's physiology has been restored. Despite the widespread acceptance of the use of DCS there are few series in the literature documenting the use of the technique, especially from low/middle-income countries. This retrospective audit of a prospectively maintained database comes from a busy trauma unit
Key messages

- The damage control surgery (DCS) patient demonstrates physiological derangement. A significant proportion ( $81 \%$ ) were injuries secondary to penetrating trauma.

- The decision to perform DCS must be made early and communicated appropriately to all those managing the patient.

- The indications for DCS still rely heavily on surgical judgement.

- Major colonic injuries should not be repaired. These injuries should be ligated and placed back inside the abdomen.

- Any complex operative procedures should be avoided in favour of minimalistic, temporising measures.

in South Africa. Our objectives were to describe the spectrum and outcome of patients requiring DCS, to benchmark our experience against that reported from other centres and countries and to extract the pertinent teaching lessons from these data. Physiological parameters, and four comprehensive scores, namely penetrating abdominal trauma index (PATI), injury severity score (ISS), abbreviated injury scale (AIS)-abdomen and AIS-chest, were used to assess this benchmark. The spectrum of solid organ injuries is also presented.

\section{METHODS}

\section{Clinical setting}

KwaZulu-Natal (KZN) province is located on the east coast of South Africa and has a population of over 11 million people. Fifty per cent of the population resides in the rural areas. The city of Pietermaritzburg is the largest city in the interior of the province and has a population of 1 million people. The Pietermaritzburg Metropolitan Trauma Service (PMTS) provides trauma care to the city of Pietermaritzburg, KZN province, South Africa, as well as to the predominantly rural western third of the province, KZN. It also serves as the referral centre for 19 other rural hospitals within the western third of the province, and has a total catchment population of over 3 million people. All patients over the age of 15 years undergoing a laparotomy for trauma over the period from December 2012 to July 2016 were retrieved from the trauma registry. The PMTS maintains a prospectively entered electronic surgical registry known as the Hybrid Electronic Medical 
Registry (HEMR), which commences in December 2012. All surgical patients are captured on this system.

\section{Participants}

The details of all patients over the age of 15 who required a laparotomy for trauma between December 2012 and July 2016 were retrieved from the HEMR. All those who required a DCS were then selected out for more in-depth analysis. Once these two groups had been broadly defined they were compared in terms of their physiology and outcome. The DCS cohort was then analysed in more detail.

\section{Variables}

Physiological parameters were assessed including: systolic BP (SBP), diastolic BP (DBP), HR, RR, $\mathrm{SpO}_{2}, \mathrm{pH}, \mathrm{pO}_{2}(\mathrm{kPa})$, $\mathrm{pCO}_{2}(\mathrm{kPa})$, base excess $(\mathrm{BE}, \mathrm{mEq} / \mathrm{L})$ and $\mathrm{HCO}_{3}(\mathrm{mEq} / \mathrm{L})$. Visceral injuries assessed included: small bowel (SB), liver, large bowel (LB), diaphragm, intra-abdominal vascular injury (IAVI), stomach, spleen, pancreas, kidney and duodenum. Injury mechanism was divided into blunt versus penetrating, and penetrating was then further subdivided into gunshot wound (GSW) versus stab wound (SW). A calculation of four comprehensive scores was performed, including PATI, ISS, AIS-abdomen and AIS-chest.

\section{Statistical analysis}

Statistical analysis was performed using STATA V.15.0@. Physiological parameters were assessed using unpaired t-test, and categorical variables assessed with $\mathrm{X}^{2}$ test.

\section{RESULTS}

A total of 562 patients underwent trauma laparotomy during the period under review. A total of 99 of these (18\%) had a DCS procedure versus $463(82 \%)$ non-DCS. The mechanism was penetrating trauma in $81 \%$ of cases $(453 / 562)$. A great proportion of trauma victims were male $(503 / 562,90 \%)$, with a mean age of $29.5 \pm 10.8$.

\section{Presenting physiology and time}

A comparison of presenting physiological parameters for DCS versus non-DCS procedures was made (table 1). Those with DCS has higher lactate, HR, RR, as well as lower SBP, DBP, $\mathrm{SpO}_{2}, \mathrm{pH}, \mathrm{BE}$ and $\mathrm{HCO}_{3}$ (all $\mathrm{p}<0.001$ ). There was no difference in $\mathrm{pO}_{2}(\mathrm{p}=0.895)$ or $\mathrm{pCO}_{2}(\mathrm{p}=0.182)$ between groups. An overall mortality rate of $32 \%$ was recorded for DCS versus $4 \%$ for non-DCS $(\mathrm{p}<0.001)$. The mean time of a damage control procedure was $97 \mathrm{~min}( \pm 52)$ vs $101 \mathrm{~min}( \pm 48)$ for non-DCS $(\mathrm{p}=0.529)$.

\section{The DCS cohort}

Out of the 99 patients who underwent DCS, there were 32 mortalities $(32 \%)$. The mean age was 33.6 years $( \pm 12.3)$. The majority of cases were male $(n=84,85 \%)$ versus female $(n=15$, $15 \%)$. The mean physiological parameters for the DCS patient demonstrated acidosis $(\mathrm{pH} 7.28 \pm 0.15)$ with a raised lactate $(5.25 \mathrm{mmol} / \mathrm{L} \pm 3.71)$. The majority of cases $(71,72 \%)$ were for penetrating trauma, of which the majority $(n=46,65 \%)$ were secondary to GSW. The most common organ injury was to the $\mathrm{SB}, \mathrm{n}=49$ (49\%), with the least common being the kidney and duodenum, both $\mathrm{n}=12(12 \%)$. Demographic data are displayed in table 1 .
Table 1 Presenting demographics and physiology for DCS versus non-DCS cases

\begin{tabular}{|c|c|c|c|}
\hline & DCS & Non-DCS & $P$ values \\
\hline Total=562 (\%) & $99(18)$ & $463(82)$ & \\
\hline Sex: M/F (\%/\%) & $84 / 15(85 / 15)$ & $419 / 44(90 / 10)$ & - \\
\hline Mean age $( \pm S D)$ & $33.6( \pm 12.3)$ & $28.6( \pm 10.3)$ & - \\
\hline Physiology & $\mathrm{n}(\mathrm{SD})$ & $\mathrm{n}(\mathrm{SD})$ & \\
\hline Lactate & $5.25( \pm 3.71)$ & $2.63( \pm 2.55)$ & $<0.001$ \\
\hline SBP & $110( \pm 24)$ & $122( \pm 19)$ & $<0.001$ \\
\hline DBP & $63( \pm 21)$ & $72( \pm 16)$ & $<0.001$ \\
\hline$H R(\min )$ & $109( \pm 23)$ & $96( \pm 21)$ & $<0.001$ \\
\hline$R R(\min )$ & $25( \pm 8)$ & $20( \pm 5)$ & $<0.001$ \\
\hline $\begin{array}{l}\mathrm{SpO}_{2} \text { (oxygen } \\
\text { saturations, \%) }\end{array}$ & $94( \pm 7)$ & $96( \pm 4)$ & $<0.001$ \\
\hline $\mathrm{pH}$ & $7.28( \pm 0.15)$ & $7.38( \pm 0.09)$ & $<0.001$ \\
\hline $\mathrm{pO}_{2}(\mathrm{~mm} \mathrm{Hg})$ & $10.7( \pm 6)$ & $10.8( \pm 6)$ & 0.895 \\
\hline $\mathrm{pCO}_{2}(\mathrm{~mm} \mathrm{Hg})$ & $5.3( \pm 1.6)$ & $5.2( \pm 1.0)$ & 0.182 \\
\hline BE (base excess, mEq/L) & $-7.14( \pm 0.72)$ & $-2.06( \pm 5.52)$ & $<0.001$ \\
\hline $\mathrm{HCO}_{3}(\mathrm{mEq} / \mathrm{L})$ & $18.86( \pm 5.65)$ & $22.83( \pm 4.15)$ & $<0.001$ \\
\hline Mortality & $32(32)$ & $19(4)$ & $<0.001$ \\
\hline
\end{tabular}

Statistical comparison is made using unpaired t-test for continuous variables and $\mathrm{X}^{2}$ test for categorical variables.

DBP, diastolic BP; DCS, damage control surgery; SBP, systolic BP.

Values in bold are statistically significant at the $5 \%$ level

\section{Impact of mechanism}

Table 2 compares the different organs injured between blunt and penetrating mechanisms. Penetrating injuries had significantly higher rates of the following injuries compared with blunt: LB ( $41 \%$ vs $11 \%, \mathrm{p}=0.04)$, diaphragm ( $30 \%$ vs $7 \%$, $\mathrm{p}=0.017)$, IAVI $(28 \%$ vs $7 \%, \mathrm{p}=0.023)$ and duodenal $(75 \%$ vs $25 \%, p=0.001$ ). For the penetrating subgroup, GSW had significantly higher rates of the following injuries compared with SW: liver $(41 \%$ vs $20 \%, \mathrm{p}=0.070)$, LB ( $50 \%$ vs $24 \%, \mathrm{p}=0.033$ ), diaphragm ( $39 \%$ vs $12 \%, \mathrm{p}=0.017)$ and stomach $(40 \%$ vs $12 \%$, $\mathrm{p}=0.026)$.

\section{Spectrum of injuries}

The total number of abdominal organ injuries was counted for each case. These included injuries to the SB, liver, LB, diaphragm, IAVI, stomach, spleen, pancreas, kidney and duodenum. The numbers of organs injured were divided into subgroups of $\leq 1$, 2-3 and 4+. Penetrating injuries had a significantly higher number of $4+$ injuries compared with blunt (23\% vs $4 \%)$ (Table 3A). Within the penetrating subgroup, GSW had the greatest frequency of multiple organ injuries compared with SW (33\% vs $4 \%$ involving $4+$ organs) (Table 3B). The mean scores for DCS versus non-DCS were as follows: PATI $17.4( \pm 13.2)$ vs $13.6( \pm 10.4), \mathrm{p}=0.058$; ISS $13.8( \pm 8.2)$ vs $12.5( \pm 8.0)$, $\mathrm{p}=0.208$; AIS-abdomen $3.3( \pm 0.8)$ vs $3.0( \pm 1.0), \mathrm{p}=0.045$; AIS-chest $0.67( \pm 1.2)$ vs $0.56( \pm 1.1), \mathrm{p}=0.431$ (table 2$)$.

\section{Management of injuries}

A total of 15 liver injuries were packed; in two cases the liver injuries were simply drained and in one case each the liver was sutured or a necrotic segment debrided. A total of 25 SB injuries were repaired, 22 were ligated and 25 repaired, and 27 underwent a resection and anastomosis. Of the SB injuries repaired, the American Association for the Surgery of Trauma (AAST) grade ranged from 2 to 5 . A total of 20 large bowel injuries were ligated, and 10 underwent primary repair and 2 primary diversion. The AAST 
Table 2 Comparison of organ injury and mechanism in DCS versus non-DCS cases

\begin{tabular}{|c|c|c|c|}
\hline & DCS & Non-DCS & \multirow[b]{2}{*}{$P$ values } \\
\hline & n (\%) & n (\%) & \\
\hline \multicolumn{4}{|l|}{ Organs (total) } \\
\hline SB (216) & $49(50)$ & $167(36)$ & 0.014 \\
\hline LB (141) & $32(32)$ & $109(24)$ & 0.067 \\
\hline Liver (112) & $34(34)$ & $78(17)$ & $<0.001$ \\
\hline Diaphragm (110) & $23(23)$ & $87(19)$ & 0.312 \\
\hline Stomach (100) & $21(21)$ & $79(17)$ & 0.327 \\
\hline Spleen (55) & $14(14)$ & $41(9)$ & 0.108 \\
\hline Intra-abdominal vessel (53) & $22(22)$ & $31(7)$ & $<0.001$ \\
\hline Kidney (42) & $12(12)$ & $30(6)$ & 0.053 \\
\hline Pancreas (41) & $13(13)$ & $28(6)$ & 0.014 \\
\hline Duodenum (31) & $12(12)$ & 19 (4) & 0.003 \\
\hline \multicolumn{4}{|l|}{ Mechanism } \\
\hline Blunt & $28(28)$ & $81(17)$ & 0.014 \\
\hline Penetrating & $71(72)$ & $382(83)$ & \\
\hline \multicolumn{4}{|l|}{ Penetrating mechanism } \\
\hline GSW & $46(65)$ & $117(31)$ & 0.001 \\
\hline SW & $25(35)$ & $265(69)$ & \\
\hline Scoring & $\mathrm{n}( \pm \mathrm{SD})$ & $\mathrm{n}( \pm \mathrm{SD})$ & \\
\hline PATI & $17.4( \pm 13.2)$ & $13.6( \pm 10.4)$ & 0.058 \\
\hline ISS & $13.8( \pm 8.2)$ & $12.5( \pm 8.0)$ & 0.208 \\
\hline AlS-abdomen & $3.3( \pm 0.8)$ & $3.0( \pm 1.0)$ & 0.045 \\
\hline AIS-chest & $0.67( \pm 1.2)$ & $0.56( \pm 1.1)$ & 0.431 \\
\hline
\end{tabular}

Statistical comparison is made using $\mathrm{X}^{2}$ test for categorical variables and unpaired t-test for numerical variables.

AIS, abbreviated injury scale; DCS, damage control surgery; GSW, gunshot wound; ISS, injury severity score; LB, large bowel; PATI, penetrating abdominal trauma index; SB, small bowel; SW, stab wound.

Values in bold are statistically significant at the $5 \%$ level

grades of those repaired were: grade 1 (3), grade 2 (2), grade 3 (3) and grade 4 (1). In seven cases, a renal injury was dealt with by nephrectomy and in five cases the perirenal haematoma was simply not explored. Four IAVIs were repaired. These included injuries to the external iliac vein and artery, the aorta, and two inferior vena cava injuries. A total of 15 vascular injuries were ligated. These included the following injuries: LB mesentery (3), right gastroepiploic artery (1), middle colic artery (1), sacral venous

Table 3 (A)The number of organs injured compared between blunt and penetrating mechanisms for all 99 DCS cases. (B)The number of organs injured compared between GSW and SW mechanisms for all 71 penetrating DCS cases

\begin{tabular}{lrrrl}
\hline \multirow{4}{*}{ Mechanism } & \multicolumn{4}{l}{ Number of organs injured } \\
\cline { 2 - 5 } (A) & \multicolumn{1}{l}{$2-3$} & $4+$ & Total \\
\hline Blunt (\%) & $19(68)$ & $8(29)$ & $1(4)$ & 28 \\
\hline Penetrating (\%) & $30(42)$ & $25(35)$ & $16(23)$ & 71 \\
\hline Total (\%) & $49(49)$ & $33(33)$ & $17(17)$ & $99(100)$ \\
$\quad$ P value & 0.028 & & & \\
(B) & & & & \\
\hline GSW (\%) & $11(24)$ & $20(44)$ & $15(33)$ & 46 \\
\hline SW (\%) & $19(76)$ & $5(20)$ & $1(4)$ & 25 \\
\hline Total (\%) & $30(42)$ & $25(35)$ & $16(23)$ & $71(100)$ \\
\hline P value & 0.001 & & & \\
\hline
\end{tabular}

DCS, damage control surgery; GSW, gunshot wound; SW, stab wound. plexus (1), right external iliac vein (1), pancreaticoduodenal vein (1), splenic artery (1), superior mesenteric vein and inferior mesenteric artery (1), left external iliac vein (1), SB mesentery (1), left common iliac vein (1), sigmoid artery and vein (1), and left renal vein (1). Two vascular injuries to the liver were managed by packing alone. Primary closure or the abdomen was performed in 26 cases, and temporary abdominal closure in 73 patients.

\section{DISCUSSION}

DCS is derived from the US Navy, and refers to the emergency measures needed to keep a ship afloat until definitive repairs can be undertaken. It has a long prehistory and in 1908, the Australian-born Scottish surgeon James Pringle described the packing of liver injuries. ${ }^{3}$ Modern DCS was described by Rotondo et al in 1993. ${ }^{2}$ They demonstrated a significant survival benefit in DCS compared with definitive laparotomy for patients with severe trauma.

However, the indications for DCS still rely heavily on surgical judgement and in this cohort of compromised patients, the margin for error is extremely small and poor decision-making can have significant negative sequela. Most trauma surgeons emphasise that both anatomic and physiological factors must be considered when deciding to adopt a DCS approach. These criteria include an arterial $\mathrm{pH}<7.2$, SBP persistently $<90 \mathrm{~mm}$ $\mathrm{Hg}$, as well as injuries to the pancreatic-duodenal complex and to the liver. ${ }^{1}$ Our cohort demonstrated physiological compromise as evidenced by the elevated mean lactate at $5.75( \pm 3.71)$ and mean BE of $-7.14( \pm 0.72)$ (Table 1$)$. The mechanism of trauma also appears to be very predictive of the need for DCS with the well over two-thirds of the patients requiring DCS having sustained $(72 \%)$ penetrating torso trauma, which is associated with a greater number of intra-abdominal injuries than blunt trauma (Table 3A). In the penetrating cohort, GSWs are more likely to require DCS than SWs as reflected by the increased number of intra-abdominal injuries associated with GSW to the abdomen (SW) (table 3B). A third of GSW injuries presented with injuries to more than four intra-abdominal structures.

DCS techniques eschew complex operative procedures in favour of minimalistic and temporising procedures. Reviewing the techniques used in this cohort suggests that the principles of DCS are being applied incompletely. Packing of liver injuries is now widely accepted and was the most common management of liver injuries in our setting. Non-expanding perirenal haematomas can be safely left unexplored in the acute setting, if exploration is undertaken then it is highly likely that a nephrectomy will be necessary. For these solid organs it would appear that our staff are well versed in DCS and tend to apply the approach appropriately to these injuries. The management of visceral injuries in this cohort however suggests that decision-making for these injuries is more opaque. Major colonic injuries should not be repaired primarily, neither should they undergo primary diversion. The role of primary diversion of colonic injuries during the initial operation should be extremely limited. If the patient cannot withstand a primary repair, then the injury should be ligated and placed back inside the abdomen. The high rates of primary repair of SB and colonic injuries during DCS suggest that the decision to opt for a DCS procedure is not being made timeously enough and that surgeons are tending to use DCS as a bailout option. The fact that the operative length between DCS and non-DCS procedures was not significantly different is reflective of this. With vascular injuries staff are more likely to adopt a DCS approach and almost all non-essential major vessels (15) were simply ligated. The four vessels which were repaired were 
Table 4 An international comparison of the demographics, physiology and outcome of DCS laparotomy

\begin{tabular}{|c|c|c|c|c|}
\hline & Rotondo et $a l^{2}(n=24)$ & Johnson et $a l^{4}(\mathrm{n}=21)$ & Kisat et $a l^{5}(n=47)$ & Present study $(n=99)$ \\
\hline Country & USA & USA & Pakistan & South Africa \\
\hline Age (years) & 30.6 & 25.6 & $33( \pm 15)$ & $33.6( \pm 12.3)$ \\
\hline Gender, M/F & $23 / 1$ & $21 / 0$ & $43 / 4$ & $84 / 15$ \\
\hline Penetrating mechanism (\%) & $24(100)$ & $21(100)$ & $32(68)$ & $71(72)$ \\
\hline SBP & $108( \pm 25)$ & $122( \pm 24)$ & $81( \pm 32)$ & $110( \pm 24)$ \\
\hline $\mathrm{pH}$ & $7.20( \pm 0.18)$ & $7.18( \pm 0.15)$ & $7.06( \pm 0.6)$ & $7.28( \pm 0.15)$ \\
\hline Survival (\%) & $14(58)$ & $19(90)$ & $26(55)$ & $67(68)$ \\
\hline
\end{tabular}

\pm denotes SD.

DCS, damage control surgery; SBP, systolic BP.

major vessels and external iliac vein and artery in one case, aorta, and two Inferior vena cava (IVC) injuries. Patients who undergo DCS should have their abdomen left open to prevent the development of intra-abdominal hypertension. However, this was only performed in $73 \%$ of cases, once again suggesting deficits in the understanding of DCS among our staff.

Our data are similar to that reported from major international series as shown in table 4. Both the demographics and the presenting physiology appear to be similar. ${ }^{245}$ There is no significant variation in survivability in our study (2012-2017) $(68 \%)$ versus the Pakistani group ${ }^{5}(1996-2011)$ (55\%) versus Rotondo et al (USA) (1993) (58\%) ${ }^{2}$; however, Johnson et al $(1997-2000)^{4}$ have survival rates of $90 \%$. The international consensus that physiological derangement should supersede anatomic consideration is shared in Brazil $^{6}$ and India. ${ }^{7}$ This is an important lesson as prolonged operating prior to adopting a DCS approach is not prudent. The decision to opt for DCS should be made early. One of the major limitations of this study is that the surgical decision-making process remains opaque and is almost impossible to tease out with a retrospective analysis. DCS should be a conscious decision made extremely early in the care pathway. Unfortunately, DCS is frequently used as a bailout procedure when the surgeon realises the magnitude of the derangement and suddenly beats a hasty retreat. The two situations are not analogous. Our data suggest that there is an incomplete understanding of the principles of DCS even in a high-volume centre such as ours. DCS techniques seem to well applied to solid visceral and vascular injuries, however they are applied inconsistently to SB and colonic injuries. In addition, there appears to be incomplete understanding about the optimal approach to managing the abdominal wound in these patients with critical injury.

\section{Lessons learnt}

Damage control is a minimalistic, truncated procedure. The fact that the length of procedure across DCS and non-DCS groups in this series was not significantly different is reflective of an incomplete understanding of the principles of DCS and this is especially apparent in the management of SB and colonic injuries and of the abdominal incision.

\section{Relevance to the Medical Officer}

The arena of warfare is changing. Enduring operations such as those in Afghanistan commonly saw casualties bypass the Role 1 treatment facility and head straight for the Role 2 enhanced facility at Camp Bastion. As operations become less enduring, without the support of a nearby Role 2 facility, the Medical Officer at a Role 1 will become more integral in providing damage control resuscitation, and damage control procedures should form the very foundation of a military surgeon's skill set.

\section{CONCLUSION}

Just under $20 \%$ of trauma laparotomies require DCS. In this cohort of patients, the mortality rate is just under one-third. Further attention must be paid to refining the appropriate indications for DCS as the margin for error in such a cohort is very small and poor decision-making is difficult to correct. The major lesson from this analysis is that the decision to perform DCS must be made early and communicated appropriately to all those managing the patient. Although DCS approaches are applied appropriately to solid organ and vascular injuries, the same cannot be said for the management of enteric injuries and of the abdominal incision. Further refinement of our algorithms is necessary to assist with surgical decision-making in these patients.

Contributors All authors contributed to the writing and editing of this article.

Funding The authors have not declared a specific grant for this research from any funding agency in the public, commercial or not-for-profit sectors.

Competing interests None declared.

Patient consent Not required.

Ethics approval Biomedical Research Ethics Committee (BREC) of the University of KwaZulu-Natal (reference: BE207/09 and BCA 221/13).

Provenance and peer review Not commissioned; externally peer reviewed.

Data sharing statement Any data can be available upon request to the corresponding author.

(c) Article author(s) (or their employer(s) unless otherwise stated in the text of the article) 2018. All rights reserved. No commercial use is permitted unless otherwise expressly granted.

\section{REFERENCES}

1 Roberts DJ, Zygun DA, Faris PD, et al. Opinions of Practicing Surgeons on the Appropriateness of Published Indications for Use of Damage Control Surgery in Trauma Patients: An International Cross-Sectional Survey. J Am Coll Surg 2016;223:515-29.

2 Rotondo MF, Schwab CW, McGonigal MD, et al. 'Damage control': an approach for improved survival in exsanguinating penetrating abdominal injury. J Trauma 1993:35:375-82. discussion 382-3.

3 Pringle JH. Notes on the Arrest of Hepatic Hemorrhage Due to Trauma. Ann Surg 1908:48:541-9.

4 Johnson JW, Gracias VH, Schwab CW, et al. Evolution in damage control for exsanguinating penetrating abdominal injury. J Trauma 2001:51:261-71.

5 Kisat M, Zafar SN, Hashmi ZG, et al. Experience of damage control trauma laparotomy in a limited resource healthcare setting: A retrospective Cohort Study. Int I Surg 2016;28:71-6.

6 Pimentel SK, Rucinski T, Meskau MPA, et al. Damage control surgery: are we losing control over indications? Rev Col Bras Cir 2018;45.

7 Rao PP, Singh DV. Combat surgery: Status of tactical abbreviated surgical control. Med J Armed Forces India 2017:73:407-9. 